(6)

OPEN ACCESS

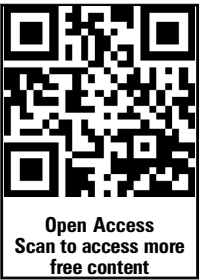

Handling editor Tore K Kvien

- Additional material is published online only. To view please visit the journal online (http://dx.doi.org/10.1136/ annrheumdis-2013-204067).

1 Department of Rheumatology, Orthopaedics and Dermatology, School of Medicine, University of Nottingham, Nottingham, UK

${ }^{2}$ Division of Rheumatology, Allergy and Immunology, Chang Gung Memorial Hospital, Taoyuan, Taiwan ${ }^{3}$ Division of Epidemiology and Public Health, School of Medicine, University of Nottingham, Nottingham, UK ${ }^{4}$ Department of Public Health, College of Medicine, Chang Gung University, Taoyuan, Taiwan

${ }^{5}$ Biostatistics Core Laboratory, Molecular Medicine Research Centre, Chang Gung University, Taoyuan, Taiwan

\section{Correspondence to} Dr Chang-Fu Kuo, Academic Rheumatology, Clinical Sciences Building, City Hospital, Nottingham NG51PB, UK; zandis@gmail.com; mbxck2@nottingham.ac.uk

WZ and MD joint senior authors

Received 3 June 2013 Revised 22 August 2013 Accepted 3 November 2013 Published Online First 21 November 2013

\title{
Familial aggregation of gout and relative genetic and environmental contributions: a nationwide population study in Taiwan
}

\author{
Chang-Fu Kuo, ${ }^{1,2}$ Matthew J Grainge, ${ }^{3}$ Lai-Chu See, ${ }^{4,5}$ Kuang-Hui Yu, ${ }^{2}$ \\ Shue-Fen Luo, ${ }^{2}$ Ana M Valdes, ${ }^{1}$ Weiya Zhang, ${ }^{1}$ Michael Doherty ${ }^{1}$
}

ABSTRACT

Objective To examine familial aggregation of gout and to estimate the heritability and environmental contributions to gout susceptibility in the general population.

Methods Using data from the National Health Insurance (NHI) Research Database in Taiwan, we conducted a nationwide cross-sectional study of data collected from 22643748 beneficiaries of the NHI in 2004; among them 1045059 individuals had physician-diagnosed gout. We estimated relative risks (RR) of gout in individuals with affected first-degree and second-degree relatives and relative contributions of genes (heritability), common environment shared by family members and non-shared environment to gout susceptibility.

Results RRs for gout were significantly higher in individuals with affected first-degree relatives (men, 1.91 (95\% Cl 1.90 to 1.93); women, 1.97 (95\% Cl 1.94 to 1.99)) and also in those with affected second-degree relatives (men, $1.27(95 \% \mathrm{Cl} 1.23$ to 1.31$)$; women, $1.40(95 \% \mathrm{Cl} 1.35$ to 1.46$))$. RRs ( $95 \% \mathrm{Cls})$ for individuals with an affected twin, sibling, offspring, parent, grandchild, nephew/niece, uncle/aunt and grandparent were 8.02 (6.95 to 9.26), 2.59 (2.54 to 2.63), 1.96 (1.95 to 1.97$), 1.93$ (1.91 to 1.94$), 1.48$ (1.43 to 1.53$), 1.40$ (1.32 to 1.47$), 1.31$ (1.24 to $1.39)$, and $1.26(1.21$ to 1.30$)$, respectively. The relative contributions of heritability, common and non-shared environmental factors to phenotypic variance of gout were $35.1,28.1$ and $36.8 \%$ in men and 17.0, 18.5 and $64.5 \%$ in women, respectively.

Conclusions This population-based study confirms that gout aggregates within families. The risk of gout is higher in people with a family history. Genetic and environmental factors contribute to gout aetiology, and the relative contributions are sexually dimorphic.

\section{INTRODUCTION}

Gout is the most common inflammatory joint disease $^{1-4}$ with an impact on morbidity ${ }^{5-7}$ and premature mortality. ${ }^{8-10}$ The disease is heritable, as suggested by familial clustering of the disease; ${ }^{11-20}$ however, the existence of many known risk factors, such as male gender, increasing age, ${ }^{21} 22$ obesity, ${ }^{23}$ chronic renal impairment, ${ }^{24}$ hypertension, ${ }^{25}{ }^{26}$ long-term use of diuretics ${ }^{27}$ and certain diets with high purine ${ }^{28}$ and alcohol, ${ }^{29}$ also supports a strong environmental contribution. Currently, the balance between genetic and environmental contributions is still unclear.

High heritability of hyperuricaemia, ${ }^{30}$ the main driver of urate crystal deposition and the development of gout, has led to efforts to identify susceptibility genes. A large familial segregation study has demonstrated significant heritability for hyperuricae$\mathrm{mia}^{30}$ and specific genetic associations, particularly genes involved in renal urate clearance, have been identified that mechanistically might explain genetic susceptibility to hyperuricaemia. ${ }^{31-34}$ Despite the strong evidence supporting a genetic contribution to hyperuricaemia, studies concerning the relative contributions of genetic and environmental factors to gout are rare. A complex segregation analysis conducted in aborigines in Taiwan showed a substantial genetic component for gout, ${ }^{35}$ but a recent classic twin study, with 514 all-male twin pairs in the US, paradoxically found significant heritability for hyperuricaemia but not for clinical gout. ${ }^{36}$ Additionally, efforts largely failed to identify susceptibility genes to gout beyond genes controlling serum urate concentration, thus questioning the role of genetic factors in gout. ${ }^{34}$

Therefore, we undertook the first nationwide population-based study to estimate the degree of familial aggregation of gout and the extent to which heritability and a common familial environment might each account for familial aggregation. We studied this in Taiwan because, first, Taiwan has one of the highest reported estimates of gout prevalence worldwide ${ }^{37}$ and, second, there is an established nationwide health insurance database containing sufficient demographic, family history and medical data on the entire Taiwanese population to allow us to address these questions.

\section{METHODS}

The study was approved by the Institutional Review Board of Chang Gung Memorial Hospital (approval number 101-2178C).

\section{Source of data}

The primary data source came from the National Health Insurance Research Database (NHIRD), which contains registration information and original claims data on all beneficiaries of NHI in Taiwan since its establishment in 1995. All entries for an individual are linked by a unique personal identifier assigned to each Taiwanese resident, which allows accurate linkage of records from the 
registration files and from the original claims data. Before release for research, personal identifiers are deidentified to ensure confidentiality.

The registry of beneficiaries, one of the registration files, contains details of demographics, residence, kinship relationships, occupation categories, insurance status and insurance amount of all beneficiaries of NHI. Claims data on all outpatient visits, inpatient care and pharmacy dispensing were recorded in specific datasets with information, such as dates of events, medical diagnoses, medical expenditure and details of prescriptions, operations, examinations and procedures.

\section{Study population and classification}

The study population consisted of all NHI beneficiaries (11360 576 men; 11283172 women) in 2004, representing $99.8 \%$ of the total population of Taiwan at the end of $2004 .{ }^{38}$ Enrolled individuals were classified according to the affection status of gout of their first-degree and second-degree relatives who were registered in the NHI before 2004.

\section{Identification of cases with gout}

The primary case definition of gout was having a physicianrecorded diagnosis of gout (International Classification of Diseases, Ninth Revision [ICD-9] code: 274.x) together with at least one prescription containing gout-specific medications (colchicine, benzbromarone, allopurinol, probenecid, sulfinpyrazone) at either an outpatient or emergency visit during 20002004. An alternative definition, used for sensitivity analysis, was having two outpatient or emergency visits with a physicianrecorded diagnosis of gout during 2000-2004. An identical case definition of gout was used for all individuals and their relatives.

\section{Identification of first-degree and second-degree relatives and family ascertainment}

The registry of beneficiaries specifies relationships between the insured person who pays the fee, and his/her dependents, allowing parent-offspring relationships and spouses to be identified directly. Among 28402865 individuals registered with the NHI during 1996-2010, 21009551 pairs of parent-offspring relationships were identified. Full siblings were identified as individuals who shared the same parents. Twins were full siblings who have the same date of birth ( \pm 1 day). Second-degree relatives were ascertained based on the aforementioned relationships. These links allowed the identification of 4191274 families spanning 2-5 generations.

\section{Demographics and socioeconomic information}

We also incorporated socioeconomic factors, including residence, occupations and income levels, to reflect population stratification with the aboriginals (with significantly higher prevalence of gout $^{39}$ ) and Han people in Taiwan. For details of these factors, please refer to the online supplementary materials.

\section{Statistical analysis}

The prevalence of gout was calculated for the general population and for individuals who had an affected spouse and/or affected relatives. Any individual fulfilling the case definitions of gout was defined as a prevalent case. For prevalence of gout in individuals with affected first-degree and second-degree relatives, age and sex were taken into account and age-standardised and sex-standardised prevalence $(95 \% \mathrm{CI})$ was determined. The standard population used was the general population of Taiwan in 2004.
The degree of familial aggregation of gout was estimated using the relative risk (RR), which was calculated as the adjusted prevalence ratio between individuals with affected relatives and the entire population of Taiwan in $2004^{40}$ The marginal Cox proportional hazard model with an equal follow-up time for all subjects with robust sandwich estimate, ${ }^{41} 42$ adjusted for age, place of residence, income, occupation and family size, was used to optimise the estimate of the RR. Because case clustering within a family may occur, the robust sandwich estimate was used when calculating confidence bounds. ${ }^{41}$ The RR was estimated for individuals with different family relatives affected with gout, including first-degree and second-degree relatives affected, and for the number of affected first-degree relatives (father, mother, son, daughter, brother, sister).

We used the standard ACE model to examine the influences of additive genetic (A), common environmental factors shared by family members (C) and non-shared environmental factors (E) accounting for variance in a phenotype $(\mathrm{P})$. This model can be expressed as:

$$
\sigma_{\mathrm{P}}^{2}=\sigma_{\mathrm{A}}^{2}+\sigma_{\mathrm{C}}^{2}+\sigma_{\mathrm{E}}^{2}
$$

where $\sigma_{\mathrm{p}}^{2}=$ total phenotypic variance; $\sigma_{\mathrm{c}}^{2}=$ common environmental variance; $\sigma_{\mathrm{c}}^{2}=$ common environmental variance and $\sigma_{\mathrm{E}}^{2}=$ nonshared environmental variance.

The heritability was defined as the proportion of phenotypic variance that is attributable to genetic factors and can be expressed as $\sigma_{\mathrm{A}}^{2} / \sigma_{\mathrm{p}}^{2}$ and the familial transmission was expressed as $\left(\sigma_{\mathrm{A}}^{2}+\sigma_{\mathrm{C}}^{2}\right) / \sigma_{\mathrm{p}}^{2}$, which is the sum of heritability and common environmental variances.

We used the polygenic liability model to calculate both measures. $^{43-45}$ For details of this model, please see the online supplementary material. We used the sibling RR, spouse RR and the prevalence of gout in the general population $(p)$ to calculate the familial transmission and the heritability, which were expressed as

$$
\begin{aligned}
\text { Familial transmission } & =\frac{\mathrm{T}_{0}-\mathrm{T}_{1} \times \sqrt{1-\left(\mathrm{T}_{0}^{2}-\mathrm{T}_{1}^{2}\right) \times\left(1-\left(\mathrm{T}_{0} / \mathrm{i}\right)\right)}}{\mathrm{a}_{\mathrm{R}} \times\left[\mathrm{i}+\mathrm{T}_{1}^{2} \times\left(\mathrm{i}-\mathrm{T}_{0}\right)\right]} \\
\text { Heritability } & =\frac{\mathrm{T}_{\mathrm{s}}-\mathrm{T}_{1} \times \sqrt{1-\left(\mathrm{T}_{\mathrm{s}}^{2}-\mathrm{T}_{1}^{2}\right) \times\left(1-\left(\mathrm{T}_{\mathrm{s}} / \mathrm{i}\right)\right)}}{\mathrm{a}_{\mathrm{R}} \times\left[\mathrm{i}+\mathrm{T}_{1}^{2} \times\left(\mathrm{i}-\mathrm{T}_{\mathrm{s}}\right)\right]}
\end{aligned}
$$

where $\quad \mathrm{T}_{0}=\Phi^{-1}(1-\mathrm{p}) ; \quad \mathrm{T}_{\mathrm{s}}=\Phi^{-1}(1-$ spouse $\mathrm{RR} \times \mathrm{p})$; $\mathrm{T}_{1}=\Phi^{-1}(1-$ sibling $\mathrm{RR} \times \mathrm{p}) ; \mathrm{p}=$ prevalence of gout in the normal population); $\mathrm{a}_{\mathrm{R}}$ : the additive genetic relationship between the relatives, for full sibling, $a_{R}=0.5 ; i=z / p ; z$, the height of the standard normal curve pertaining to gout prevalence, and $\Phi$, standard normal cumulative distribution function. ${ }^{46}$

Therefore, the common environmental component was the difference between familial transmission and heritability. Since the epidemiologic and clinical features of gout are sexually dimorphic, and hence, equal genetic variances in both sexes may not hold true, ${ }^{47}$ we estimated sex-specific familial transmission and heritability using respective sex-specific populations.

All analyses were performed for primary and alternative case definitions of gout. A 2-sided p value 0.05 was considered statistically significant. All analyses were performed using SAS V.9.3 (SAS institute, Cary, North Carolina, USA).

\section{RESULTS}

\section{Gout prevalence in individuals with affected family} members versus the general population

We identified 802765 men and 242294 women with gout in 2004 giving a crude prevalence of gout of $4.62 \%(95 \% \mathrm{CI}$ 
$4.61 \%$ to $4.63 \%$ ) (see online supplementary table S1). Men had a significantly higher prevalence $(7.07 \%, 95 \%$ CI $7.05 \%$ to $7.08 \%)$ than women $(2.15 \%$, 95\% CI $2.14 \%$ to $2.16 \%)$. We identified 1663904 individuals with at least one affected firstdegree relative, and 604468 individuals with at least one affected second-degree relative. The standardised prevalence of gout in individuals with affected first-degree and second-degree relatives were $13.37 \%(95 \%$ CI $13.35 \%$ to $13.39 \%)$ and $10.05 \%$ (95\% CI $10.03 \%$ to $10.06 \%$ ) in men, and $4.16 \%(95 \%$ CI $4.15 \%$ to $4.18 \%)$ and $3.01 \%$ (95\% CI $3.00 \%$ to $3.02 \%)$ in women, respectively. Figure $1 \mathrm{a}$ and $1 \mathrm{~b}$ show age-specific and sex-specific prevalence of gout in men and women which, at all ages, is higher in individuals with affected first-degree relatives than in those with second-degree relatives and the general population.

\section{Family exposure and risk of gout}

The risk of gout was significantly higher in individuals with affected first-degree relatives than in the general population, the RRs being 1.91 (95\% CI 1.90 to 1.93 ) in men and 1.97 (95\% CI 1.94 to 1.99 ) in women (see online supplementary table S2). Individuals with affected second-degree relatives also had an increased risk of gout, albeit significantly lower than those with affected first-degree relatives, with RRs of 1.27 (95\% CI 1.23 to $1.31)$ in men and 1.40 (95\% CI 1.35 to 1.46$)$ in women. Figure 2 shows that individuals with an affected twin had the highest risk, followed by individuals with an affected sibling, then individuals with an affected offspring and, finally, individuals with an affected parent. Same-sex twins had the highest $\mathrm{RR}$, being higher in female-female twin pairs than male-male twin pairs. The RRs for gout in individuals with any category of affected second-degree relative (table 1) were lower than RRs in those with affected first-degree relatives (figure 2). The RRs also increased with the number of affected first-degree relatives. Compared with the general population, individuals with one, two or three or more categories of affected first-degree relatives had RRs (95\% CIs) of 1.87 (1.86 to 1.89 ), 3.22 (3.15 to 3.29) and 4.96 (4.64 to 5.30), respectively. This trend was more prominent in women (figure 3 ).

Familial aggregation of gout was evident in individuals with affected biological relatives, and also in those with affected spouses. The RRs were $1.66(1.65-1.68)$ in men with an affected wife and 1.65 (95\% CI 1.64 to 1.67 ) in women with an affected husband.

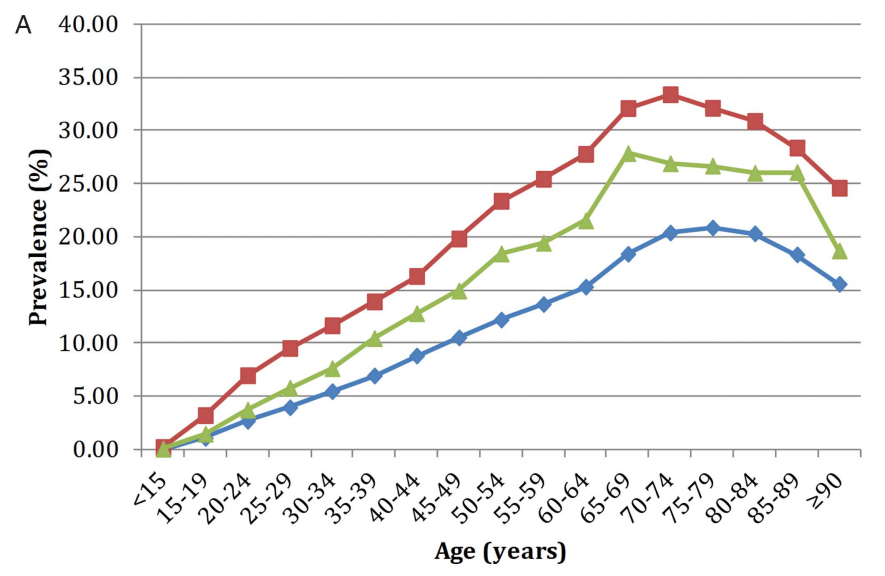

Relative contributions of genetic, common and non-shared environmental factors

To separate the influences of genes and environment, we calculated heritability and familial transmission. In men, heritability was $35.1 \%$ (95\% CI $34.1 \%$ to $36.0 \%)$ and familial transmission was $63.2 \%$ (95\% CI $61.8 \%$ to $64.7 \%$ ); whereas in women, they were $17.0 \%$ (95\% CI $15.0 \%$ to $19.0 \%$ ) and $35.5 \%(95 \% \mathrm{CI}$ $33.1 \%$ to $37.8 \%$ ), respectively. Figure 4 shows the relative contributions of genetic (heritability), common environmental and non-shared environmental components to the phenotypic variances of gout.

\section{Sensitivity analysis}

We also used alternative case definition of gout to do sensitivity analysis. The results were very similar to our primary analysis (please see online supplementary table S3, figures S1 and S2).

\section{DISCUSSION}

This nationwide population study has confirmed familial aggregation of gout by demonstrating a greater prevalence and RR of gout for individuals with affected family members compared to the general population. The risk of gout is increased more by having affected first-degree relatives than having affected second-degree relatives, and appears 'dose-dependent' in that the risk increases with the number of affected relatives. These results confirm the long-held belief that gout clusters within families and supports an important contribution of common familial factors in predisposing to the development of gout.

However, biological relatives tend to share similar environmental and lifestyle risk factors in addition to genes; both contribute to familial aggregation. Therefore, we examined the risk associated with having a spouse who has gout on the assumption that any increased risk from this predominantly reflects predisposition from environmental and lifestyle factors common to family members. We found that the relative contributions differ between men and women; however, overall it appears that genetic factors play a smaller, but still substantial, role than environmental factors in the aetiology of gout. Our findings are consistent with the relative paucity of gout susceptibility genes identified by genome-wide association studies in comparison with greater numbers of genes associated with risk of hyperuricaemia, which has a greater heritability. ${ }^{31-34}$

Consistent with previous studies, our findings provide strong evidence to support the existence of familial aggregation of gout. ${ }^{11-19}$ However, current evidence concerning the relative

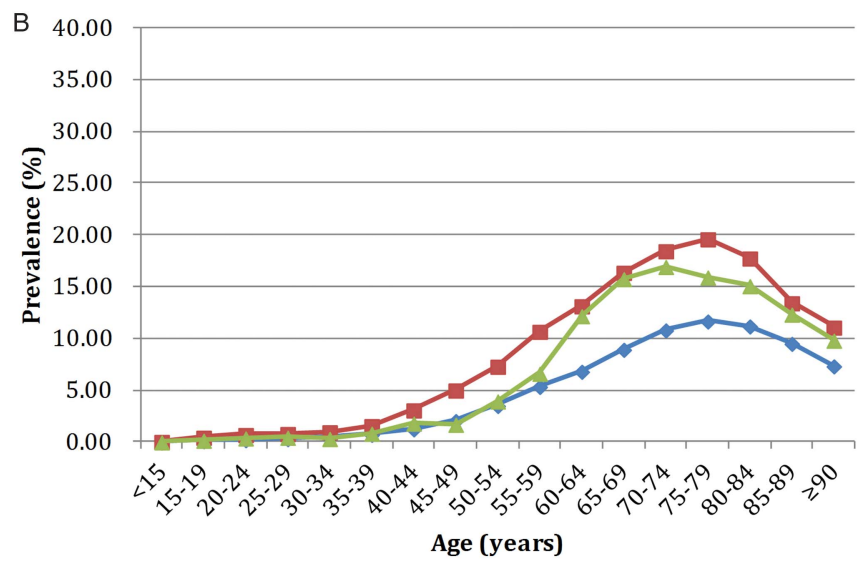

Figure 1 Age-specific prevalence of gout in men (A) and women (B) according to the affection status of relatives (red, individuals with affected first-degree relatives; green, individuals with affected second-degree relatives; blue, the general population). 


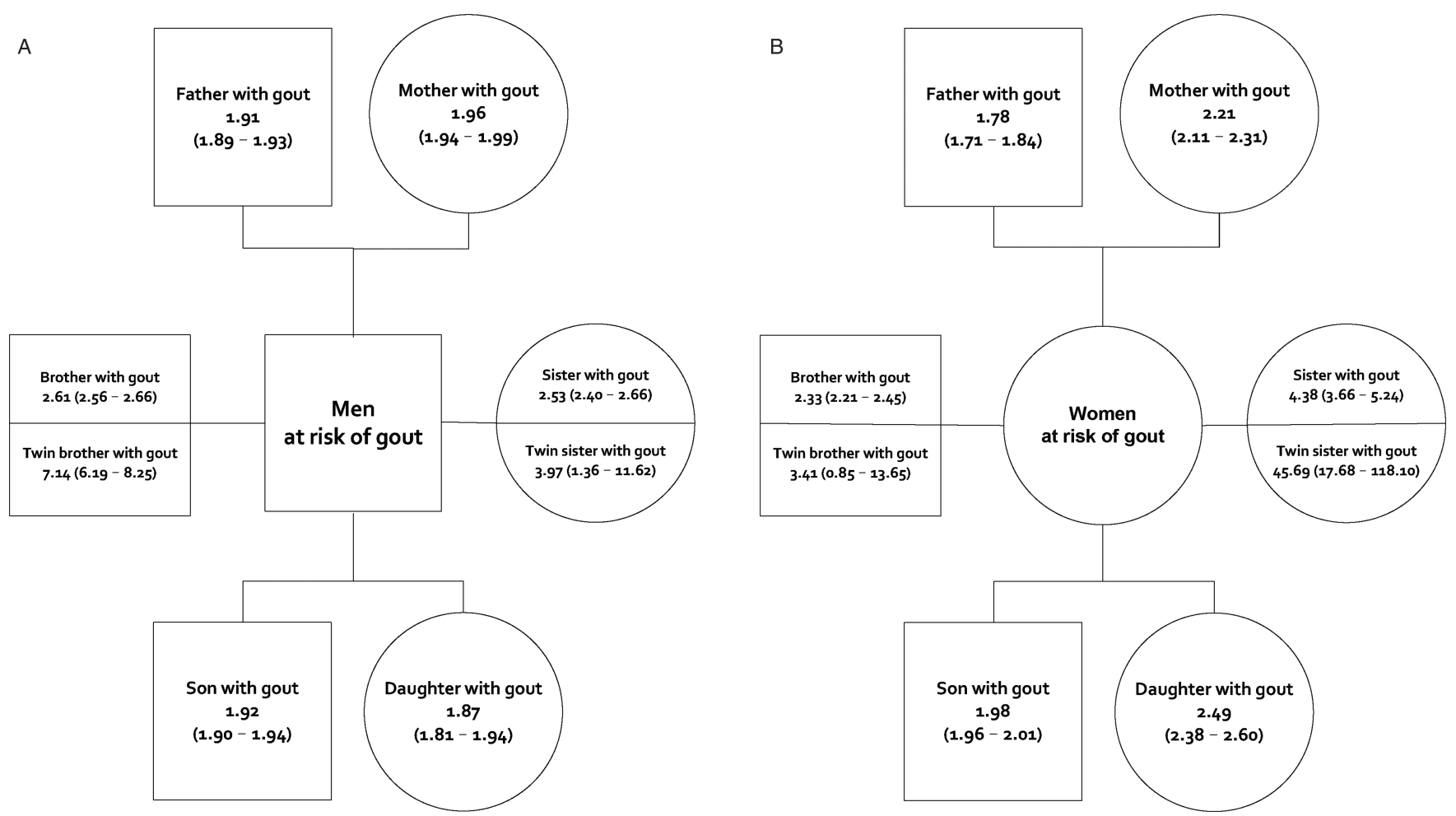

Figure 2 Relative risks $(95 \% \mathrm{Cl})$ of gout among (A) men and (B) women with affected first-degree relatives (square, male; circle, female) in comparison with the general population in Taiwan in 2004.

contributions of genetic and environmental exposures for gout susceptibility is limited. A complex segregation study conducted in the aborigines of Taiwan supported the existence of a substantial genetic predisposition to gout; however, no heritability estimate was reported. ${ }^{35}$ By contrast, one recent study of 253 monozygotic and 261 dizygotic North American male twin pairs found a significant heritability for hyperuricaemia $(49.6 \%)$ but, surprisingly, given that chronic hyperuricaemia is the key mechanism for urate crystal formation, no heritability $(0 \%$; $95 \%$ CI $0 \%$ to $61.8 \%$ ) for gout. ${ }^{36}$ Nevertheless, our whole population study provided several lines of evidence to support the existence of genetic predisposition to gout. First, our data

Table 1 Relative risk of gout among individuals with affected second-degree relatives in comparison with the general population in Taiwan in 2004

\begin{tabular}{|c|c|c|c|c|}
\hline \multirow{2}{*}{$\begin{array}{l}\text { Affected second-degree } \\
\text { relatives }\end{array}$} & \multicolumn{2}{|c|}{ Men at risk } & \multicolumn{2}{|c|}{ Women at risk } \\
\hline & $\mathbf{R R}$ & $95 \% \mathrm{Cl}$ & $\mathbf{R R}$ & $95 \% \mathrm{Cl}$ \\
\hline \multicolumn{5}{|l|}{ Grandparent } \\
\hline Grandfather & 1.18 & 1.12 to 1.25 & 1.29 & 1.10 to 1.51 \\
\hline Grandmother & 1.31 & 1.25 to 1.37 & 1.45 & 1.24 to 1.68 \\
\hline \multicolumn{5}{|l|}{ Grandchild } \\
\hline Grandson & 1.25 & 1.20 to 1.31 & 1.45 & 1.39 to 1.52 \\
\hline Granddaughter & 1.39 & 1.21 to 1.59 & 1.54 & 1.33 to 1.78 \\
\hline \multicolumn{5}{|l|}{ Uncle or aunt } \\
\hline Uncle & 1.32 & 1.24 to 1.40 & 1.19 & 0.96 to 1.45 \\
\hline Aunt & 1.21 & 0.98 to 1.48 & 0.91 & 0.41 to 2.03 \\
\hline \multicolumn{5}{|l|}{ Nephew or niece } \\
\hline Nephew & 1.42 & 1.34 to 1.51 & 1.16 & 0.95 to 1.41 \\
\hline Niece & 1.42 & 1.16 to 1.74 & 0.90 & 0.41 to 2.00 \\
\hline
\end{tabular}

on twin pairs showed significantly different risk profiles in same-sex twins compared to opposite-sex twins. Although lack of information on zygosity prevented the calculation of heritability based on twin data, the higher RR shared by same-sex (partly monozygotic) twins compared to opposite-sex (exclusively dizygotic) twins supports a genetic contribution. Second, using the spouse as an indicator of shared environmental risk, we estimated a heritability of $35.1 \%$ in men and $17.0 \%$ in

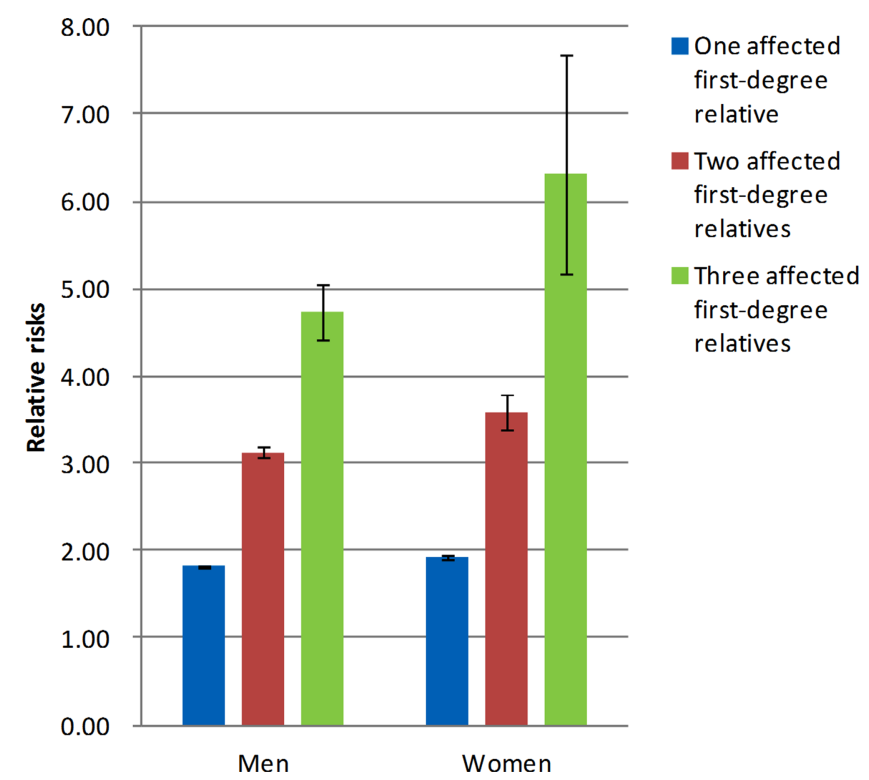

Figure 3 The 'dose-response' relationship between the numbers of affected first-degree relatives and relative risk of gout (blue: one; red: two; green: three first-degree relatives). 


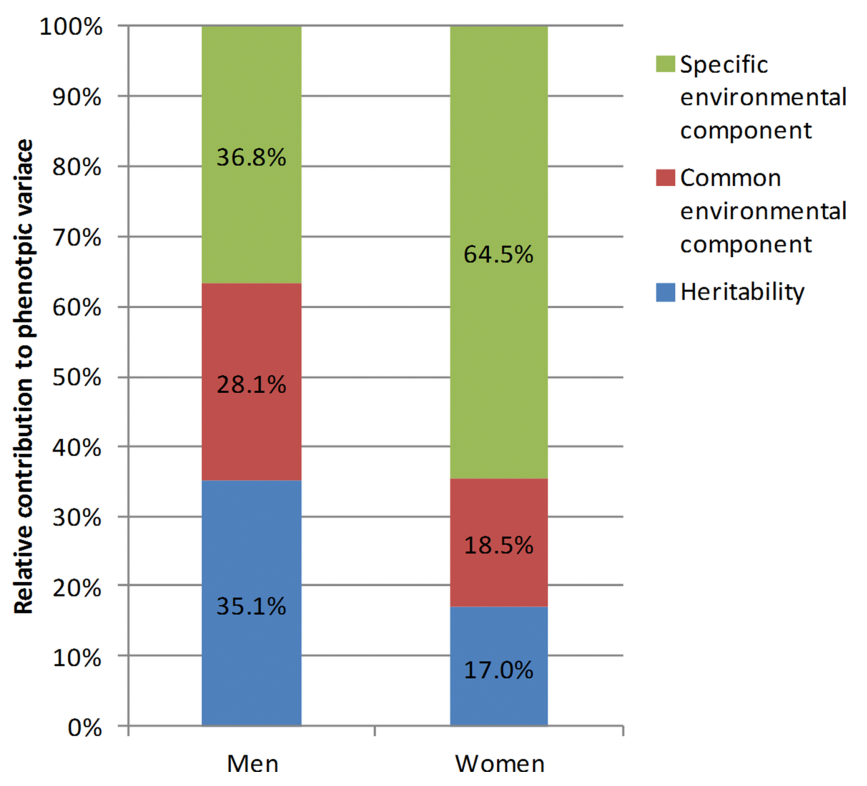

Figure 4 Relative contributions of heritability (blue), common environmental (red) and specific environmental factors (green) to phenotypic variation of gout.

women. Therefore, although not the sole explanation for familial aggregation, genetic factors in addition to environmental influences, do contribute to the development of gout.

It has long been observed that men are significantly more likely to have gout than women. ${ }^{48} 49$ Additionally, onset of gout is later in women. ${ }^{50}$ The cause of this sexual dimorphism is not clear. One explanation is the uricosuric effect of oestrogen which results in lower serum urate levels in premenopausal women. ${ }^{51}$ Therefore, prevalence of gout is generally low in premenopausal women and increases dramatically after menopause. ${ }^{52}$ Different exposure to environmental risk factors may also contribute to the sex difference. For instance, dietary calorie intake and alcohol consumption are lower in women than men in Taiwan according to a national nutrition survey. ${ }^{53} 54$ Our study shows that familial transmission and heritability are both significantly higher in men. These findings suggest that genetic and common environmental factors are the main predisposing factors to gout in men, but not in women. Therefore, the sex difference can be partly attributed to different contributions from family factors. Further study is needed to confirm this finding.

There are several limitations to the study. First, it was confined to Taiwan, so results may not be generalisable to other settings. Second, the NHIRD is primarily a health insurance database that contains limited information on criteria for clinical diagnosis. We did not have data on potential confounding factors, therefore, we cannot test the interactions between family history and other confounders and their independent contributions to the risk of gout. Further, our analysis of relative genetic and environmental contributions was based on the multifactorial liability model, and our results are subject to assumptions, so should be interpreted with caution. However, the published data on other disease, such as schizophrenia ${ }^{46}$ support the validity of this model. Finally, we cannot account for the effects of assortative mating whereby spouses are more similar for a phenotype than they would be if mating occurred at random in the population. If this assortment is not negligible, a biased estimation of relative genetic and environmental contributions may occur. ${ }^{55}$
Our main strengths include the use of data from the entire population of approximately 23 million individuals, and systematic methods to identify and ascertain first-degree and second-degree relatives, which allow very precise estimation of prevalence and RRs of gout with minimal selection bias. The virtually complete identification of gout cases, and the use of consistent case definitions for individuals at risk and their relatives, ensured the absence of information bias. Furthermore, we used prospectively recorded data for diagnosis, for construction of family relationships and for ascertaining socioeconomic information, thus minimising recall bias and other errors associated with self-reporting.

The present study provides quantitative estimates of familial RR and heritability for gout in an entire population of Taiwan. Our results confirm the clinical belief that gout clusters within families, and that genetic and environmental components contribute to its aetiology. Studies of familial risk in other populations are required to determine the generalisability of these findings to other populations.

Acknowledgements We would like to thank the National Science Council of Taiwan (project NSC 102-2314-B-182A-104) and Chang Gung Memorial Hospital (project CMRPG3B1671) for financial support and the University of Nottingham for methodological assistance and infrastructure. Sponsors of the study had no role in design and conduct of the study; collection, management, analysis, and interpretation of the data; and preparation, review, or approval of the manuscript. This study is based on the National Health Insurance Research Database, which is provided by the Bureau of National Health Insurance, Department of Health, and managed by the National Health Research Institutes, Taiwan. The interpretation and conclusions contained herein do not represent positions of the Bureau of National Health Insurance or the National Health Research Institutes.

Contributors Study concept and design: C-FK, WZ and MD; acquisition of data: C-FK, L-CS, K-HYu and S-FL; analysis and interpretation of data: C-FK, MJG, L-CS, AMV, WZ and MD; drafting of the manuscript: C-FK and WZ; critical revision of the manuscript for important intellectual content: C-FK, MJG, L-CS, K-HY, S-FL, AMV, WZ and MD; statistical analysis: C-FK, MJG, L-CS and WZ; obtaining funding: C-FK, L-CS, K-HY and S-FL; administrative, technical, or material support: MJG, L-CS, K-HY, S-FL, AMV, WZ and MD; study supervision: WZ, MD and MJG.

Funding Chang Gung Memorial Hospital, and the National Science Council in Taiwan.

Competing interests None.

Ethics approval Chang Gung Memorial Hospital.

Provenance and peer review Not commissioned; externally peer reviewed.

Data sharing statement Additional data and statistical codes are available on request from the corresponding author at zandis@gmail.com

Open Access This is an Open Access article distributed in accordance with the Creative Commons Attribution Non Commercial (CC BY-NC 3.0) license, which permits others to distribute, remix, adapt, build upon this work non-commercially, and license their derivative works on different terms, provided the original work is properly cited and the use is non-commercial. See: http://creativecommons.org/ licenses/by-nc/3.0/

\section{REFERENCES}

1 Choi HK, Mount DB, Reginato AM, et al. Pathogenesis of gout. Ann Intern Med 2005; 143:499-516.

2 Annemans L, Spaepen E, Gaskin M, et al. Gout in the UK and Germany: prevalence, comorbidities and management in general practice 2000-2005. Ann Rheum Dis 2008;67:960-6.

3 Zhu Y, Pandya BJ, Choi HK. Prevalence of gout and hyperuricemia in the US general population: the National Health and Nutrition Examination Survey 20072008. Arthritis Rheum 2011;63:3136-41.

4 Winnard D, Wright C, Taylor WJ, et al. National prevalence of gout derived from administrative health data in Aotearoa New Zealand. Rheumatology (Oxford) 2012;51:901-9.

5 Ab. Usbott RD, Brand FN, Kannel WB, et al. Gout and coronary heart disease: the Framingham Study. J Clin Epidemiol 1988;41:237-42.

6 Krishnan E, Baker JF, Furst DE, et al. Gout and the risk of acute myocardial infarction. Arthritis Rheum 2006;54:2688-96.

7 Sheane BJ, Cunnane G. Tophaceous gout and chronic kidney disease. J Clin Rheumatol 2007;13:293 
8 Choi HK, Curhan G. Independent impact of gout on mortality and risk for coronary heart disease. Circulation 2007;116:894-900.

9 Krishnan E, Svendsen K, Neaton JD, et al. Long-term cardiovascular mortality among middle-aged men with gout. Arch Intern Med 2008;168:1104-10.

10 Kuo CF, See LC, Luo SF, et al. Gout: an independent risk factor for all-cause and cardiovascular mortality. Rheumatology (Oxford) 2010;49:141-6.

11 Mituszova $M$, Judak $A$, Poor $G$, et al. Clinical and family studies in Hungarian patients with gout. Rheumatol Int 1992:12:165-8.

12 Blumberg BS. Heredity of gout and hyperuricemia. Arthritis Rheum 1965;8:627-47.

13 Emmerson BT. Heredity in primary gout. Australas Ann Med 1960;9:168-75.

14 Hauge M, Harvald B. Heredity in gout and hyperuricemia. Acta Med Scand 1955:152:247-57.

15 Smyth CJ, Cotterman CW, Freyberg RH. The genetics of gout and hyperuricaemia Ann Rheum Dis 1948;7:248

16 Smyth CJ, Cotterman CW, Freyberg RH. The genetics of gout and hyperuricaemia; an analysis of 19 families. J Clin Invest 1948;27:749-59.

17 Grahame R, Scott JT. Clinical survey of 354 patients with gout. Ann Rheum Dis 1970;29:461-8.

18 Copeman WSC. A short history of the gout and the rheumatic diseases. Berkeley: University of California Press, 1964.

19 Cobb S. The frequency of the rheumatic diseases. Cambridge: Harvard University Press, 1971.

20 Reginato AM, Mount DB, Yang I, et al. The genetics of hyperuricaemia and gout. Nat Rev Rheumatol 2012;8:610-21.

21 Arromdee $\mathrm{E}$, Michet CJ, Crowson CS, et al. Epidemiology of gout: is the incidence rising? J Rheumatol 2002;29:2403-06.

22 Mikuls TR, Saag KG. New insights into gout epidemiology. Curr Opin Rheumatol 2006:18:199-203.

23 Choi HK, Atkinson K, Karlson EW, et al. Obesity, weight change, hypertension, diuretic use, and risk of gout in men: the health professionals follow-up study. Arch Intern Med 2005; 165:742-8.

24 Edwards NL. The role of hyperuricemia and gout in kidney and cardiovascular disease. Cleve Clin J Med 2008;75(Suppl 5):S13-16.

25 Bhole V, de Vera M, Rahman MM, et al. Epidemiology of gout in women: fifty-twoyear followup of a prospective cohort. Arthritis Rheum 2010;62:1069-76.

26 Choi HK, Atkinson K, Karlson EW, et al. Obesity, weight change, hypertension, diuretic use, and risk of gout in men-The health professionals follow-up study. Arch Intern Med 2005;165:742-8.

27 Hueskes BA, Roovers EA, Mantel-Teeuwisse AK, et al. Use of diuretics and the risk of gouty arthritis: a systematic review. Semin Arthritis Rheum 2012:41:879-89.

28 Choi HK, Curhan G. Gout: epidemiology and lifestyle choices. Curr Opin Rheumatol 2005; 17:341-5.

29 Choi HK, Atkinson K, Karlson EW, et al. Alcohol intake and risk of incident gout in men: a prospective study. Lancet 2004;363:1277-81.

30 Wilk JB, Djousse L, Borecki I, et al. Segregation analysis of serum uric acid in the NHLBI Family Heart Study. Hum Genet 2000;106:355-9.

31 Vitart V, Rudan I, Hayward C, et al. SLC2A9 is a newly identified urate transporter influencing serum urate concentration, urate excretion and gout. Nat Genet 2008:40:437-42.

32 Kolz M, Johnson T, Sanna S, et al. Meta-analysis of 28,141 individuals identifies common variants within five new loci that influence uric acid concentrations. PLOS Genet 2009:5:e1000504.
33 Dehghan A, Kottgen A, Yang Q, et al. Association of three genetic loci with uric acid concentration and risk of gout: a genome-wide association study. Lancet 2008;372:1953-61.

34 Kottgen A, Albrecht E, Teumer A, et al. Genome-wide association analyses identify 18 new loci associated with serum urate concentrations. Nat Genet 2013;45:145-54.

35 Wang WH, Chang SJ, Wang TN, et al. Complex segregation and linkage analysis of familial gout in Taiwanese aborigines. Arthritis Rheum 2004;50:242-6.

36 Krishnan E, Lessov-Schlaggar CN, Krasnow RE, et al. Nature versus nurture in gout: a twin study. Am J Med 2012;125:499-504.

37 Lin KC, Lin HY, Chou P. Community based epidemiological study on hyperuricemia and gout in Kin-Hu, Kinmen. J Rheumatol 2000;27:1045-50.

38 Directorate General of Budget, Accounting and Statistics, Executive Yuan, Taiwan. Population by sex, rate of population increase, average persons per household, density and natural increase rate. http://eng.stat.gov.tw/lp.asp?ctNode $=2265 \&$ CtUnit=1072\&BaseDSD=36\&MP=5 (accessed 15 Aug 2013).

39 Chou CT, Lai JS. The epidemiology of hyperuricaemia and gout in Taiwan aborigines. Br J Rheumatol 1998;37:258-62.

40 Risch N. Linkage strategies for genetically complex traits. I. Multilocus models. Am J Hum Genet 1990;46:222-8.

41 Lin DY. Cox regression analysis of multivariate failure time data: the marginal approach. Stat Med 1994; 13:2233-47.

42 Lee J, Chia KS. Estimation of prevalence rate ratios for cross sectional data: an example in occupational epidemiology. Br J Ind Med 1993;50:861-2.

43 Falconer DS. The inheritance of liability to diseases with variable age of onset, with particular reference to diabetes mellitus. Ann Hum Genet 1967;31:1-20.

44 Reich T, James JW, Morris CA. The use of multiple thresholds in determining the mode of transmission of semi-continuous traits. Ann Hum Genet 1972;36:163-84.

45 Reich T, Rice J, Cloninger CR, et al. The use of multiple thresholds and segregation analysis in analyzing the phenotypic heterogeneity of multifactorial traits. Ann Hum Genet 1979;42:371-90

46 Wray NR, Gottesman II. Using summary data from the danish national registers to estimate heritabilities for schizophrenia, bipolar disorder, and major depressive disorder. Front Genet 2012;3:118.

47 Ober C, Loisel DA, Gilad Y. Sex-specific genetic architecture of human disease. Nat Rev Genet 2008;9:911-22.

48 Cea Soriano L, Rothenbacher D, Choi HK, et al. Contemporary epidemiology of gout in the UK general population. Arthritis Res Ther 2011;13:R39.

49 Mikuls TR, Farrar JT, Bilker WB, et al. Gout epidemiology: results from the UK General Practice Research Database, 1990-1999. Ann Rheum Dis 2005;64:267-72

50 De Souza A, Fernandes V, Ferrari AJ. Female gout: clinical and laboratory features. J Rheumatol 2005:32:2186-8.

51 Adamopoulos D, Vlassopoulos C, Seitanides B, et al. The relationship of sex steroids to uric acid levels in plasma and urine. Acta Endocrinol (Copenh) 1977;85:198-208.

52 Hak AE, Curhan GC, Grodstein F, et al. Menopause, postmenopausal hormone use and risk of incident gout. Ann Rheum Dis 2010;69:1305-9.

53 Lin YC, Yen LL, Chen SY, et al. Prevalence of overweight and obesity and its associated factors: findings from National Nutrition and Health Survey in Taiwan, 1993-1996. Prev Med 2003;37:233-41.

54 Wu SJ, Pan WH, Yeh NH, et al. Trends in nutrient and dietary intake among adults and the elderly: from NAHSIT 1993-1996 to 2005-2008. Asia Pac J Clin Nutr 2011;20:251-65.

55 Rice TK. Familial resemblance and heritability. Adv Genet 2008;60:35-49. 